\title{
Carobomer Based Controlled Release Designs of Atorvastatin Calcium Tablets Evaluated Using Quality by Design (QbD) Approach
}

\section{Arunkanth Krishnakumar Nair ${ }^{1}$, Peddakotla Venkata Ramana ${ }^{1}$, P. Venkat Bhaskar Rao ${ }^{1}$, Bapatu Hanimi Reddy' ${ }^{2}$, Hari Kishan Reddy Ganthi', Useni Reddy Mallu' ${ }^{1}$}

${ }^{1}$ Sri Krishnadevaraya University, Anantapur, India

${ }^{2} J a w a h a r l a l$ Nehru Technological University, Hyderabad, India

Email: *arunkanthkr@gmail.com

How to cite this paper: Nair, A.K., Ramana, P.V., Rao, P.V.B., Reddy, B.H., Ganthi, H.K.R. and Mallu, U.R. (2017) Carobomer Based Controlled Release Designs of Atorvastatin Calcium Tablets Evaluated Using Quality by Design (QbD) Approach. American Journal of Analytical Chemistry, 8, 189-209.

https://doi.org/10.4236/ajac.2017.83016

Received: January 16, 2017

Accepted: March 10, 2017

Published: March 13, 2017

Copyright $\odot 2017$ by authors and Scientific Research Publishing Inc. This work is licensed under the Creative Commons Attribution International License (CC BY 4.0).

http://creativecommons.org/licenses/by/4.0/

\begin{abstract}
The study carried out here was focused on developing conventional monolithic controlled release matrix tablet of Atorvastatin calcium using carbomer as release controlling polymer. This system ensures the drug release at the alkaline $\mathrm{pH}$ region where the drug has got maximum solubility. Further the study was concentrated on comparing the impact of gelling agent polyvinyl pyrrolidone on drug release. Quality by design tools were considered during formulation development and the polymer concentrations were optimized adopting the statistical tool, design of experiments (DoE). The optimized formulation of present study exhibited desired controlled drug release characteristics in the alkaline $\mathrm{pH}$ conditions and at acidic environment the drug dissolution was minimal as intended.
\end{abstract}

\section{Keywords}

Atorvastatin Calcium Tablets, Controlled Release, Carbomer, Release Controlling Polymer, Gelling Agent, Povidone

\section{Introduction}

Over the years, researches have paid greater attention on developing controlled release dosage forms, which invariably carries significant advantage over the conventional dosage forms. The goal in designing the controlled release delivery systems reduces the dosing frequency, ensuring consistent drug delivery and maintaining the therapeutic levels. Controlled drug delivery systems provide 
better control of plasma drug concentrations and minimize the adverse effects with improved efficacy and constant delivery [1] [2] [3] [4].

Among various polymers, hydrogels have been widely used for the development of controlled release matrix tablets. The hydrogel in a swollen state maintains soft and rubbery state comparable to living tissues and displays excellent biocompatibility [5]. Carbomer offer a variety of release profile along with compatability with active ingredients and excipients and convenience of using standard manufacturing methods. Carbopol resins exhibits ideal compressibilities and makes it suitable for direct compression process [6].

Carbopol is the brand name for carbomer polymers; it's a synthetic high molecular weight crosslinked polymer of acrylic acid. It is polymerized in ethyl acetate and treated with potassium. Carbomer readily hydrates, absorbs water and swells. Its hydrophilic and cross linked structure makes it a potential candidate for controlled drug delivery systems [7].

Controlled release formulations of Atorvastatin calcium tablets were developed using the release controlling polymer carbomer and gelling agent Povidone.

The present study was focused on developing conventional monolithic controlled release matrix tablet of Atorvastatin calcium with carbomer as release controlling polymer. This system ensures the drug release at the alkaline $\mathrm{pH}$ region where the drug has got maximum solubility. Further the study was concentrated on evaluating the impact of gelling agent polyvinyl pyrrolidone (Povidone K90) on drug release.

Carbopol $^{\oplus}$ polymers have a $\mathrm{pKa}$ of 6 , so at $\mathrm{pH} 1.2$ they are virtually un-ionized; and will start to ionize at $\mathrm{pH}$ 4.5. At lower $\mathrm{pH}$ values the polymer is not fully swollen, and there are larger regions of low microviscosity; the solvent can penetrate fast and deep into the glassy core. As the $\mathrm{pH}$ increases, the ionization of the carboxylic acid groups causes maximum swelling, resulting in fewer and smaller regions of microviscosity. The rapid gel formation acts as a barrier for the release of the drug, thus prolonging the release [8] [9] [10] [11] [12].

Polyvinylpyrrolidone (Povidone) is a nonionic water-soluble polymer and is known for its gelling properties. It has got good adhesion and complex formation properties as well [13].

QbD (Quality by design) is a systematic science based approach for formulation design that begins with pre-defined objectives and emphasizes product and process understanding based quality risk management (QRM). Quality by design (QBD) based product development comprises the statistical tool, Design of experiments (DoE) for optimization and there by establishing the appropriate design space and control strategies. Quality by design (QBD) based formulation design consists of target profile design, identifying the critical quality attributes (CQA), critical process parameters (CPP) and risk assessment of material attributes on CQA's. The choice of an experimental design depends on the objectives of the experiment and the number of factors to be investigated [14] [15] [16]. Among the various designs like factorial, Randomized block designs, Response 
surface methodologies, Box-Henken etc. full factorial design was selected. A full factorial design of experiment (DOE) measures the response of every possible combination of factors and factor levels. These responses are analyzed to provide information about every main effect and every interaction effect. Design of experiments was applied for optimizing the concentration of release controlling polymer carbomer and the carbomer to povidone ratio in tablet matrix as well.

The present study was focused on designing a controlled release matrix tablet formulation for Atorvastatin Calcium tablets using anionic cross linked polymer Carbomer with a hydrophilic gelling agent Povidone. Among the various grades Carbopol 974P was chosen for the application as release controlling agent. Carbopol $974 \mathrm{P}$ is having a pKa value of 6 and it remains virtually unionized at acidic conditions resulting in minimal or no drug release at this stage. Atorvastatin calcium possess higher solubility at alkaline $\mathrm{pH}$ conditions and carbomer based matrix system ensures that the drug is completely released only at alkaline regions of above $\mathrm{pH}$ 4.5. These formulation designs were used to deliver the drug to targeted sites which eventually improves the systemic absorption and subsequently bioavailability. The dosage form designed here as carbomer based controlled release matrix system, ensuring slow release of drug in to the soluble $\mathrm{pH}$ conditions so that the bioavailability of the active can be enhanced [17] [18].

Quality by design based formulation development was performed where in the optimization done using statistical tools by Design-Expert ${ }^{\oplus}$, version 6.0 Software. The manufacturing process was performed using rapid mixer granulator, blender and Compression machine. The final product was characterized with conventional methods using High Performance liquid chromatography, Dissolution Apparatus, Differential scanning calorimetry (DSC), Scanning Electron Microscopy (SEM) and X ray diffraction spectroscopy (XRD).

\section{Materials and Methods}

\subsection{Materials}

Atorvastatin Calcium (ATC) was procured from Aurobindo pharma Ltd, India. Carbomer grades (Carbopol 974P \& 971P); were samples provided by Lubrizol Corporation. Povidone K30 and K90 were sourced from BASF, Lactose monohydrate from DFE pharma and Colloidal silicon dioxide (Grade-Aerosil 200) and magnesium stearate was procured from Evonik Industries and Nitika chemicals respectively. Mannitol from Roquette pharm and Microcrystalline Cellulose from JRS pharma were used in the trials. The tablets were compressed using KT10SS (Keumsung) compression machine and the in process checks like hardness and thickness were evaluated by Erweka hardness tester.

\subsection{Manufacturing Method}

The present study was focused on developing conventional monolithic controlled release matrix tablet with carbomer as release controlling polymer. The formulations were manufactured using high shear granulation process followed 
by lubrication and compression.

\subsection{Method of Analysis}

Drug product method is available in USP Pharmacopoeia Forum and it is yet to be official in Pharmacopoeia. Hence the dissolution studies were carried out following an in house developed method [19]. Below represents the details about the study procedure.

\subsection{Dissolution Method}

Buffer solution preparation:

1) Dissolve about $1.54 \mathrm{~g}$ of ammonium acetate in $1000 \mathrm{~mL}$ of Milli-Q water, mix well and adjust the $\mathrm{pH}$ to 4.0 with diluted glacial acetic acid.

2) Filter the solution through $0.45 \mu \mathrm{m}$ membrane filter.

Mobile phase preparation:

1) Mix Acetonitrile and buffer in the ratio of $60: 40 \mathrm{v} / \mathrm{v}$ respectively.

2) Degas in a sonicator for about 10 minutes

Chromatographic system:

1) The liquid chromatograph is equipped with a $244 \mathrm{~nm} \mathrm{UV} \mathrm{detector.}$

2) Column :Xterra RP-C8, $4.6 \times 150 \mathrm{~mm}, 5 \mu \mathrm{m}$

3) Column temperature $: 25^{\circ} \mathrm{C}$

4) Flow rate $\quad: 1.4 \mathrm{~mL} /$ minute

5) Run time : About 4 minutes

6) Injection volume $: 5 \mu \mathrm{L}$

\subsection{Assay Method}

Chromatographic Conditions-The liquid chromatograph is equipped with a $244 \mathrm{~nm}$ UV detector; Zorbax Rx-C8, $4.6 \times 250$ mm, $5 \mu \mathrm{m}$ Column; $1.5 \mathrm{~mL} / \mathrm{min}$ flow Rate; Injection Volume $-20 \mu \mathrm{L}$; Run Time $-25 \mathrm{~min}$; Temperature $-35^{\circ} \mathrm{C}$; Gradient Program.

\section{Experimental Design}

The experimental design is normally developed based on the results and understanding gained over literatures and Preformulation studies. Comprehensive preformulation study helps in understanding the physico-chemical properties of the drug molecule like solubility, stability, compatibility and solid state characteristics.

In the present study drug substance Characterisation followed by drug excipient compatibility studies were performed at Preformulation stages. The stress study samples were characterized by Differential scanning calorimetry followed by physical evaluation.

1) Hygroscopicity Studies of Atorvastatin Calcium:

The Hygroscopicity study was performed for Atorvastatin Calcium, by subjecting it to $80 \% \mathrm{RH}$ condition for $24 \mathrm{hrs}$ and determining the percent mass change. The results are tabulated in Table 1. 
Maximum Mass change in the hygroscopicity test was $0.109 \%$ under the conditions of $25^{\circ} \mathrm{C} \pm 11^{\circ} \mathrm{C}$ for $24 \mathrm{hrs}$. at $80 \% \pm 2 \% \mathrm{RH}$ (as per European pharmacopoeia). As the mass change was less than $0.2 \%$, Atorvastatin Calcium was classified as "Non hygroscopic".

2) Solubility Studies of Atorvastatin Calcium:

The solubility studies of atorvastatin calcium were performed across the Physiological pH conditions. The data is appended below in Table 2 .

3) Solid State characterization

Atorvastatin Calcium is prone for polymorphic changes. The Polymorphic form of the drug substance used in the present study is Crystalline Form I [20].

Atorvastatin Calcium API sample was analyzed by powder XRD. The diffractogram and the $2 \theta$ values are presented below in Figure 1 . The characteristic $2 \theta$ values are represented in Table 3.

The difractogram and the $2 \theta$ values are in line with that mentioned in the Active ingredient Drug Master File that claims to be of polymorphic Form I.

\section{Drug Excipient Interactions Study}

As part of the Preformulation studies the drug excipient interaction check was

Table 1. Hygroscopicity studies data of Atorvastatin calcium.

\begin{tabular}{ccccc}
\hline $\mathrm{m}_{1}(\mathrm{~g})$ & $\mathrm{m}_{2}(\mathrm{~g})$ & $\mathrm{m}_{3}(\mathrm{~g})$ & \%weight change & Hygroscopicity \\
\hline 10.322 & 20.375 & 10.053 & 0.109 & Non hygroscopic \\
8.139 & 18.401 & 10.262 & 0.058 & Non hygroscopic \\
8.323 & 18.489 & 10.166 & 0.089 & Non hygroscopic \\
\hline
\end{tabular}

$\mathrm{m}_{1}$ : Container Weight; $\mathrm{m}_{2}$ : Container Weight with sample; $\mathrm{m}_{3}$ : Container Weight with sample after storing in chamber for 24 hours.

Table 2. Atorvastatin calcium solubility results.

\begin{tabular}{cccc}
\hline \multicolumn{4}{c}{ Atorvastatin Calcium Solubility study } \\
\hline Media & Solubility $(\mathrm{mg} / \mathrm{mL})$ & $\begin{array}{c}\text { Volume of solvent } \\
\text { in } \mathrm{mL} / 1 \mathrm{~g}(\mathrm{~mL})\end{array}$ & USP Solubility scale \\
\hline $0.1 \mathrm{~N} \mathrm{HCl}$ & 0.0254 & 39370.1 & Practically insoluble \\
$0.01 \mathrm{~N} \mathrm{HCl}$ & 0.0315 & 31746.0 & Practically insoluble \\
pH 4.5 & 0.0570 & 17543.9 & Practically insoluble \\
pH 5.5 & 0.1701 & 5878.9 & Very slightly soluble \\
pH 6.8 & 0.2838 & 3523.6 & Very slightly soluble \\
\hline
\end{tabular}

Table 3. Characteristic $2 \theta$ value for crystalline form I.

\begin{tabular}{cccccccccc}
\hline S: No & 1 & 2 & 3 & 4 & 5 & 6 & 7 & 8 & 9 \\
\hline $2 \theta$ Value & 9.314 & 9.619 & 10.422 & 10.703 & 11.999 & 12.332 & 17.161 & 19.601 & 21.758 \\
\hline
\end{tabular}


performed by mixing all the excipients with drug in a ratio where the excipient concentration are maximum as compared to the proposed formulation and evaluated for any changes at initial and accelerated storage conditions [21]. Table 4 represents the drug excipient ratios selected during study.

1) Stress Testing-Differential scanning calorimetry

The compatibility of drug with chosen excipients was evaluated using Differential scanning calorimetry [22]. The Physical mix of the excipients along with drug were prepared by triturating together in a mortar and the final blend was evaluated in the Differential scanning calorimetry (DSC) apparatus Setaram DSC 131 Evo. The diffractogram at initial and after 2 weeks exposure at accelerated conditions $\left(40^{\circ} \mathrm{C} / 75 \% \mathrm{RH}\right)$ are appended below Figure 2 and Figure 3.

The difractogram ensures that the blend at initial and after exposure does not show any significant interactions

Table 4. Excipients and their ratios for compatibility study.

\begin{tabular}{cccccc}
\hline S:No & Ingredients & Ratio & S:No & Ingredients & Ratio \\
\hline 1 & Atorvastatin calcium & $\mathrm{X}$ & 5 & Lactose Monohydrate & $3 \mathrm{X}$ \\
2 & Carbopol 974P & $1 \mathrm{X}$ & 6 & Microcrystalline Cellulose & $3 \mathrm{X}$ \\
3 & Povidone K90 & $1 \mathrm{X}$ & 7 & Colloidal Silicon dioxide & $0.5 \mathrm{X}$ \\
4 & Povidone K30 & $1 \mathrm{X}$ & 8 & Magnesium Stearate & $0.5 \mathrm{X}$ \\
\hline
\end{tabular}

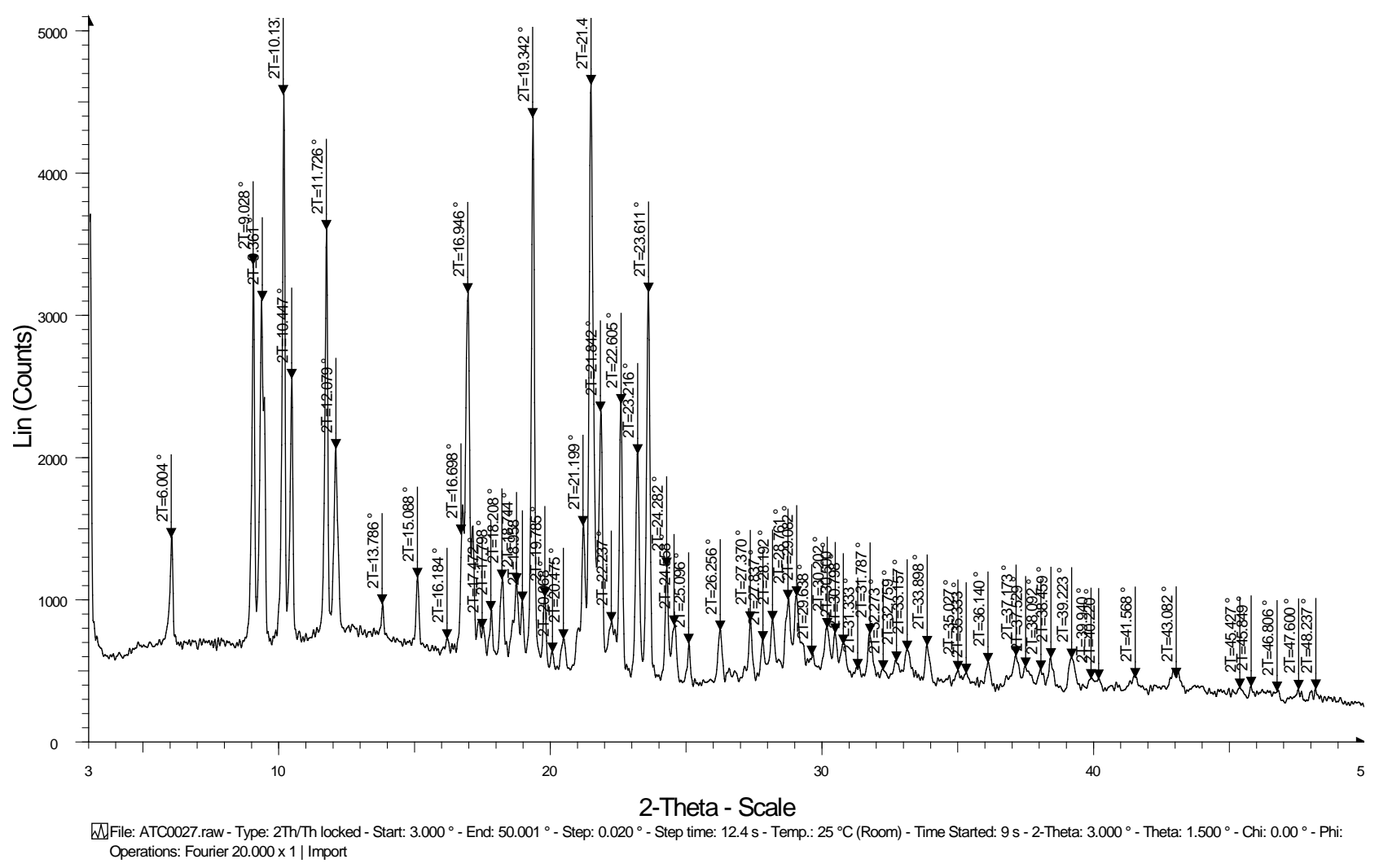

Figure 1. Difractogram of atorvastatin calcium form I. 


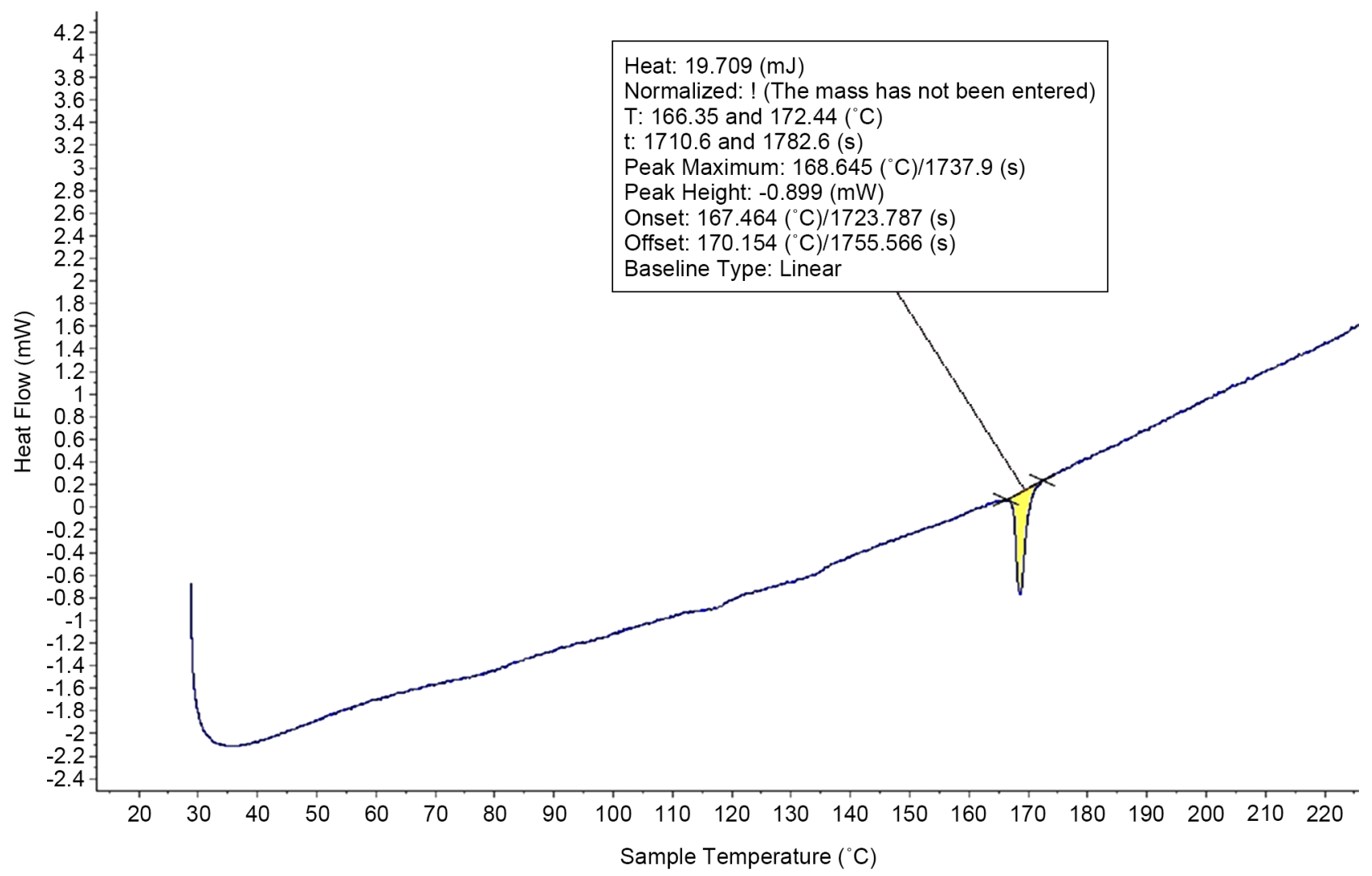

Figure 2. Difractogram of drug substance with excipients-Initial.

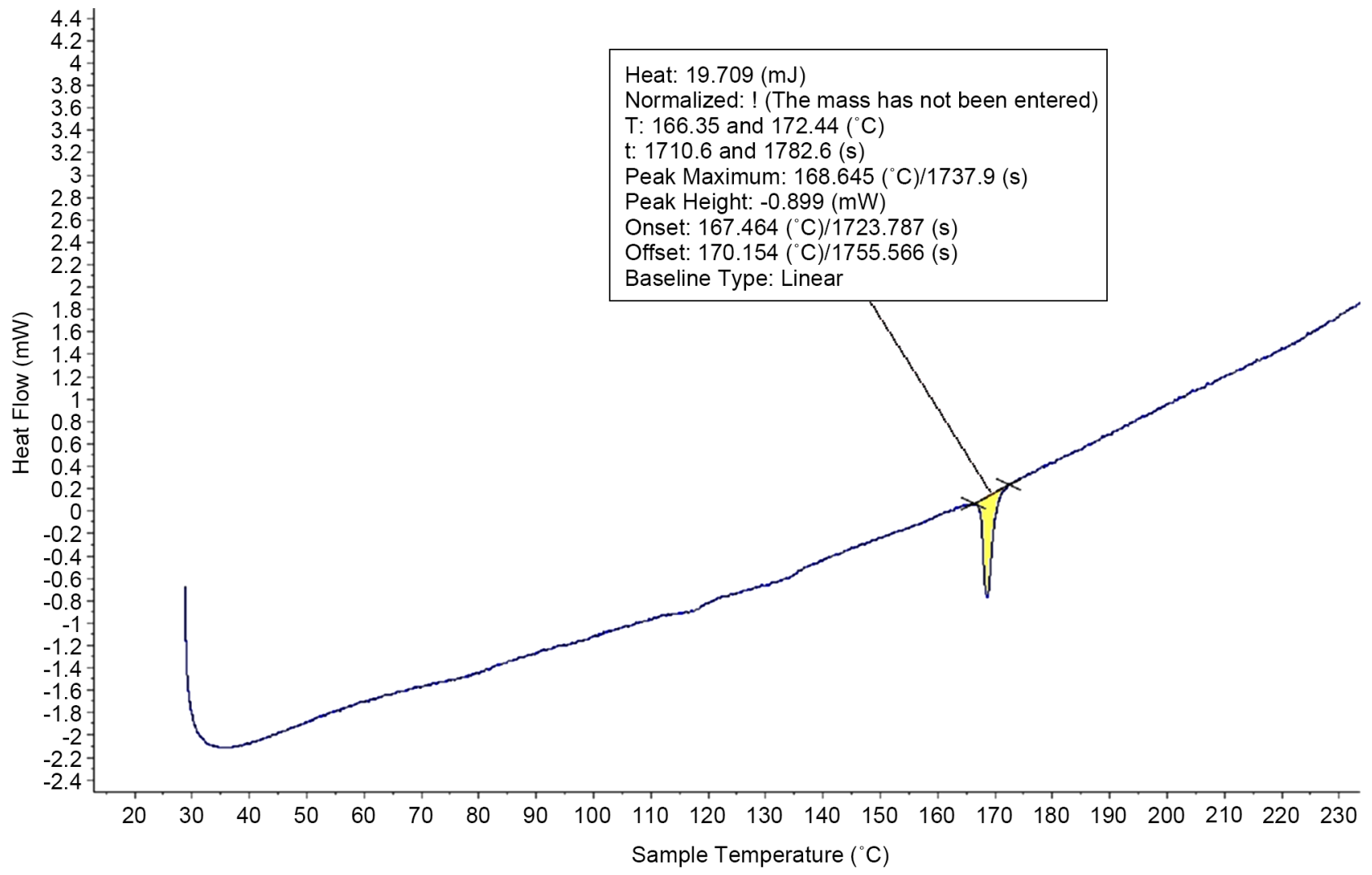

Figure 3. Difractogram of drug substance with excipients-2 weeks exposed. 


\section{2) Stress Testing-Physical evaluation}

Drug and individual excipients were weighed and triturated together in a mortar for uniform mixing [23]. The physical mix blend was sifted together through \#40 mesh screen and filled in to glass vials. The vials containing physical mix was covered with Teflon tap with perforations and exposed at $40^{\circ} \mathrm{C} / 75 \% \mathrm{RH}$ conditions. Incompatibilities were evaluated by observing the physical mixture for any color change after 2 weeks of storage under accelerated conditions. The physical observations revealed that there are no significant changes when compared with the initial blend.

\section{Formulation Design Experiments}

\subsection{Quality by Design (QBD)}

Typically, the quality by design based product development should include defining quality target profile, identifying Critical quality attributes, Critical Process parameters and risk assessment. Based on the risk assessments performed, the polymer levels and channelizing agent concentrations possess relatively high risk on drug product critical quality attribute, dissolution profile. The linkage between the process inputs (input variables and process parameters) and the critical quality attributes can be described in the design space [24] [25]. Below Table 5 and Table 6 represents the Quality target product profile (QTPP) and Critical Quality Attributes (CQA).

$\mathrm{QbD}$ is a systematic science based approach for formulation design that begins with pre-defined objectives and emphasizes product and process understanding based quality risk management (QRM). Quality by design (QBD) based product development comprises the statistical tool, Design of experiments (DoE) for optimization and there by establishing the appropriate control strategies. Quality by design (QBD) based formulation design consists of target profile design, Identifying the critical quality attributes (CQA), critical process parameters (CPP) and risk assessment of material attributes on CQA's. The choice of an experimental design depends on the objectives of the experiment and the number of factors to be investigated [26] [27].

Table 5. Quality target product profile (QTPP).

\begin{tabular}{cc}
\hline QTTP Elements & Target \\
\hline $\begin{array}{c}\text { Dosage form } \\
\text { Tosage design } \\
\text { Stability }\end{array}$ & Controlled release monolithic tablets \\
Physical properties & Sufficient hardness to withstand handling and transportation. \\
Dissolution & No significant drug release in acidic conditions \\
Polymorphism & Finished product polymorphic form (Form-I) shall be \\
\end{tabular}


Table 6. Critical quality Attributes (CQA).

\begin{tabular}{cc}
\hline Quality attributes of the drug product & Target \\
\hline Tablet weight & $120 \mathrm{mg}$ \\
Hardness & $3-5 \mathrm{kp}$ \\
Related substance & Minimum degradation \\
Assay & $95 \%-105 \%$ \\
Dissolution & NLT 75\% drug release in 12 hours \\
Polymorphism & Crystalline Form-I shall be retained during \\
\end{tabular}

\subsection{Formulation Experiments}

The formulation experiments were designed based on the literatures evaluated and preformulation studies. Atorvastatin calcium and lactose were co sifted through a cone mill with $2.0 \mathrm{~mm}$ sieve. The remaining Intragranular materials like carbomer and povidone were mixed with API \& lactose blend. The dry mix blend was granulated using water in a high speed mixer granulator. The wet granules were screened through a No. 12 mesh screen. The resulting granules were dried at $40^{\circ} \mathrm{C}-45^{\circ} \mathrm{C}$ till the moisture levels reached approximately $3 \%$. The dried granules then milled through a cone mill using $1.5 \mathrm{~mm}$ screen along with colloidal silicon dioxide and lubricated by mixing with magnesium stearate. Batch composition for the formulation trials are depicted below in Table 7. Additionally DoE study design, experimental run and responses data are compiled in Table 8, Table 9 and Table 10 respectively.

\section{Results and Discussion}

\subsection{Tabletting Properties}

The tablets were compressed at Keumsung compression machine with $6.0 \mathrm{~mm}$ diameter round shaped punches. The tablet physical properties like hardness, thickness and weight variation was evaluated. The tablets had shown sufficient hardness and other physical properties desired for handling.

All the formulation trials have shown sufficient physico chemical properties when evaluated for hardness and thickness. Tablets properties details are represented in below Table 11.

\subsection{Dissolution Characteristics}

The formulation was characterized for drug release properties in $\mathrm{pH} 6.8$ phosphate buffer for 12 hours. Figure 4 displays the dissolution profile comparison of DoE experimental batches.

Drug Release at acidic conditions:

The centrepoint formulation experiment F005 was further evaluated in $\mathrm{pH} 1.2$ buffer to ensure that minimum amount of atorvastatin is released at acidic conditions. The drug release profile is depicted below in Figure 5. 
Table 7. Batch Composition (representative) for the controlled release formulation.

\begin{tabular}{cccccc}
\hline \multirow{2}{*}{ Ingredients } & \multicolumn{5}{c}{ Composition(mg/tablet) } \\
\cline { 2 - 5 } & F001 & F002 & F003 & F004 & F005 \\
\hline Atorvastatin calcium & 20 & 20 & 20 & 20 & 20 \\
Lactose monohydrate & 40 & 40 & 40 & 40 & 40 \\
Carbomer 974P & 11 & 5 & 11 & 5 & 8 \\
Povidone K 90 & 2 & 6 & 6 & 2 & 4 \\
Microcrystalline cellulose & 44 & 46 & 40 & 50 & 45 \\
Colloidal Silicon dioxide & 1.5 & 1.5 & 1.5 & 1.5 & 1.5 \\
Magnesium stearate & 1.5 & 1.5 & 1.5 & 1.5 & 1.5 \\
Total & 120 & 120 & 120 & 120 & 120 \\
\hline
\end{tabular}

Table 8. DoE design and responses.

\begin{tabular}{|c|c|c|c|c|c|}
\hline & \multirow{2}{*}{\multicolumn{2}{|c|}{ Factors }} & \multicolumn{3}{|c|}{ Levels $(\% \mathrm{w} / \mathrm{w})$} \\
\hline & & & -1 & 0 & +1 \\
\hline A & \multicolumn{2}{|c|}{ Level of Carbomer (Carbopol 974P) } & 4.17 & 6.67 & 9.17 \\
\hline $\mathrm{B}$ & \multicolumn{2}{|c|}{ Level of Povidone (Povidone K 90) } & 1.67 & 3.34 & 5 \\
\hline & Responses & Goal & \multicolumn{3}{|c|}{ Acceptable Ranges } \\
\hline Y1 & Drug release at 1 Hour in $\mathrm{pH} 6.8$ & In range & \multicolumn{3}{|c|}{ NMT 20} \\
\hline $\mathrm{Y} 2$ & Drug release at 2 Hour in $\mathrm{pH} 6.8$ & In range & \multicolumn{3}{|c|}{$20-40$} \\
\hline Y3 & Drug release at 4 Hour in $\mathrm{pH} 6.8$ & In range & \multicolumn{3}{|c|}{$40-60$} \\
\hline Y4 & Drug release at 8 Hour in $\mathrm{pH} 6.8$ & In range & \multicolumn{3}{|c|}{ NLT 75} \\
\hline
\end{tabular}

Table 9. Range of factors and experimental run as per design expert 6.0.

\begin{tabular}{|c|c|c|c|}
\hline \multirow{3}{*}{ Std } & \multirow{3}{*}{ Run } & Factor 1 & Factor 2 \\
\hline & & A: Carbomer & B: Povidone \\
\hline & & \multicolumn{2}{|c|}{ Level (\%w/w) } \\
\hline 2 & 1 & 9.17 & 1.67 \\
\hline 3 & 2 & 4.17 & 5.00 \\
\hline 4 & 3 & 9.17 & 5.00 \\
\hline 1 & 4 & 4.17 & 1.67 \\
\hline 7 & 5 & 6.67 & 3.34 \\
\hline 5 & 6 & 6.67 & 3.34 \\
\hline 6 & 7 & 6.67 & 3.34 \\
\hline
\end{tabular}


Table 10. DoE experiments and responses compilation.

\begin{tabular}{|c|c|c|c|c|c|c|c|}
\hline \multirow{2}{*}{ Std } & \multirow{2}{*}{ Run } & Factor 1 & Factor 2 & Response 1 & Response 2 & Response 3 & Response 4 \\
\hline & & A: Carbomer & B: Povidone & Disso $1 \mathrm{hr}$ & Disso $2 \mathrm{hr}$ & Disso $4 \mathrm{hr}$ & Disso $8 \mathrm{hr}$ \\
\hline & & $\%$ & $\%$ & $\%$ & $\%$ & $\%$ & $\%$ \\
\hline 2 & 1 & 9.17 & 1.67 & 14 & 29 & 44 & 67 \\
\hline 3 & 2 & 4.17 & 5.00 & 24 & 44 & 63 & 97 \\
\hline 4 & 3 & 9.17 & 5.00 & 11 & 27 & 41 & 65 \\
\hline 1 & 4 & 4.17 & 1.67 & 26 & 47 & 66 & 96 \\
\hline 7 & 5 & 6.67 & 3.34 & 18 & 34 & 54 & 89 \\
\hline 5 & 6 & 6.67 & 3.34 & 21 & 39 & 58 & 90 \\
\hline 6 & 7 & 6.67 & 3.34 & 16 & 40 & 61 & 92 \\
\hline
\end{tabular}

Table 11. Tabletting properties of the experiments.

\begin{tabular}{cccc}
\hline Trial & Hardness $^{*}$ & Tablet weight & Thickness $^{*}$ \\
\hline F001 & 4.4 & 121.6 & 3.17 \\
F002 & 4.5 & 119.5 & 3.18 \\
F003 & 4.4 & 120.9 & 3.15 \\
F004 & 4.7 & 119.8 & 3.20 \\
F005 & 4.6 & 120.7 & 3.18 \\
F006 & 4.7 & 123.3 & 3.19 \\
F007 & 4.6 & 121.2 & 3.18 \\
\hline
\end{tabular}

${ }^{*}$ Average of 10 tablets were determined.

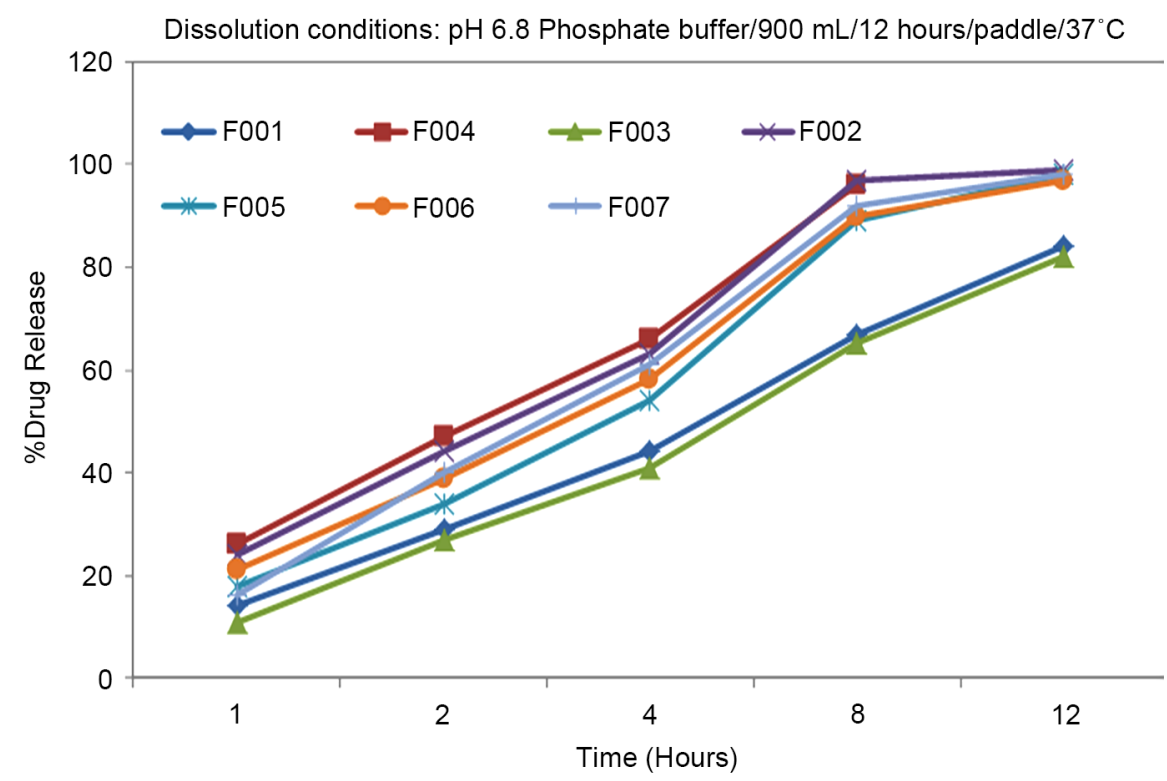

Figure 4. Dissolution profile of varying concentrations of carbomer \& povidone in $\mathrm{pH}$ 6.8 phosphate buffer. 


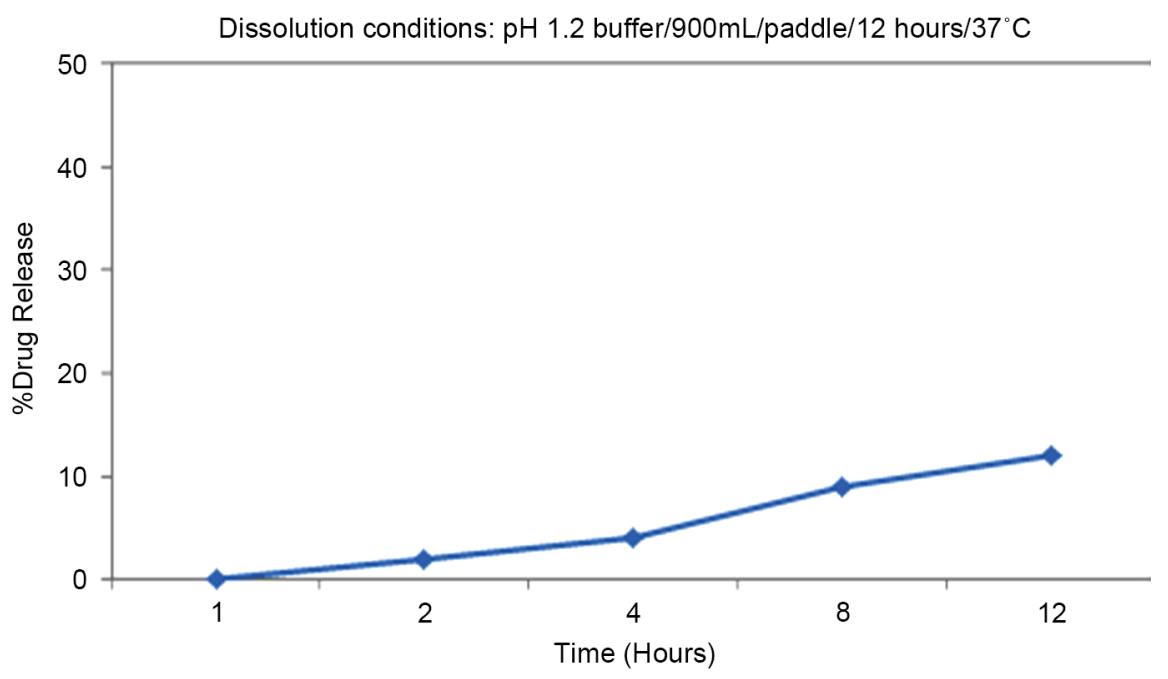

Figure 5. Dissolution profile of batch number F005 in acidic conditions (pH 1.2 buffer).

\subsection{DOE Data Analysis and Interpretation}

The data analysis was performed using Design Expert ${ }^{\oplus}$ software. ANOVA analysis represents whether model and factor are significant for the respective response or not. It is concluded to be significant if $\mathrm{p}$-value were below threshold ( $\mathrm{p}$ $=0.05$ ). Additionally, If available, the half-normal plot is used for evaluation and selection of significant factor based on the desirable linearity of remains, experimental data.

\subsubsection{Significant Factors for Dissolution at 1 Hour}

All DoE batches studied for evaluating the impact of concentration of carbomer and Povidone on drug release characteristics are shown below in Table 12.

ANOVA results show that studied polymer range model is significant when adjusted for curvature. The following ANOVA is for a Model that does not adjust for curvature. Factor A, Carbomer is having significant impact on the drug release of Atorvastatin from the formulation matrix

The Model F-value of 12.55 implies the model is significant. There is only a 3.33\% chance that a "Model F-Value" this large could occur due to noise. Values of "Prob > F" less than 0.0500 indicate model terms are significant. In this case A are significant model terms. The "Lack of Fit F-value" of 0.02 implies the Lack of Fit is not significant relative to the pure error. There is a $98.20 \%$ chance that a "Lack of Fit F-value" this large could occur due to noise. Non-significant lack of fit is good-we want the model to fit.

ANOVA and graphs indicated that the factor carbomer had significant impact on the drug release properties at intial time point.

\subsubsection{Significant Factors for Dissolution at 2 Hour}

Impact of polymers carbomer and povidone on drug release at 2 Hours were evaluated. The following ANOVA represented in Table 13 is for a model that does not adjust for curvature. This is the default model used for prediction and model plots. 
Table 12. ANOVA results of the model unadjusted for curvature.

\begin{tabular}{|c|c|c|c|c|c|c|}
\hline Source & $\begin{array}{l}\text { Sum of } \\
\text { Squares }\end{array}$ & $\mathrm{df}$ & $\begin{array}{l}\text { Mean } \\
\text { Square }\end{array}$ & F Value & $\begin{array}{c}\text { p-value } \\
\text { Prob }>\text { F }\end{array}$ & Remarks \\
\hline Model & 162.75 & 3 & 54.25 & 12.55 & 0.0333 & significant \\
\hline A-carbomer & 156.25 & 1 & 156.25 & 36.16 & 0.0092 & significant \\
\hline B-Povidone & 6.25 & 1 & 6.25 & 1.45 & 0.3153 & not significant \\
\hline $\mathrm{AB}$ & 0.25 & 1 & 0.25 & 0.06 & 0.8254 & not significant \\
\hline Residual & 12.96 & 3 & 4.32 & - & - & - \\
\hline Lack of Fit & 0.46 & 2 & 0.23 & 0.02 & 0.9820 & not significant \\
\hline Pure Error & 12.50 & 1 & 12.50 & - & - & - \\
\hline Cor Total & 175.71 & 6 & - & - & - & - \\
\hline
\end{tabular}

Table 13. ANOVA results of the model unadjusted for curvature.

\begin{tabular}{ccccccc}
\hline Source & $\begin{array}{c}\text { Sum of } \\
\text { Squares }\end{array}$ & df & $\begin{array}{c}\text { Mean } \\
\text { Square }\end{array}$ & F Value & p-value & Remarks \\
\hline Model & 312.71 & 3 & 104.24 & 14.12 & 0.0283 & significant \\
A-carbomer & 306.25 & 1 & 306.25 & 41.49 & 0.0076 & significant \\
B-Povidone & 6.21 & 1 & 6.21 & 0.84 & 0.4265 & not significant \\
AB & 0.25 & 1 & 0.25 & 0.03 & 0.8657 & - \\
Residual & 22.14 & 3 & 7.38 & - & - & - \\
Lack of Fit & 21.64 & 2 & 10.82 & 21.64 & 0.1503 & not significant \\
Pure Error & 0.50 & 1 & 0.50 & - & - & - \\
Cor Total & 334.86 & 6 & - & - & - & - \\
\hline
\end{tabular}

ANOVA interpretation and model plots reveals that the studied model is significant and the factor carbomer plays a crucial role in controlling the drug release characteristics at 2 Hour time point. However Povidone has got very minimal role and the factor interactions are also not significant.

\subsubsection{Significant Factors for Dissolution at 4 Hour}

Impact of polymers carbomer and povidone on drug release properties at 4 Hours were evaluated. The following ANOVA is for a model that does not adjust for curvature. This is the default model used for prediction and model plots. ANOVA results are tabled below in Table 14.

The Model F-value of 9.04 implies there is a $5.17 \%$ chance that a "Model F-Value" this large could occur due to noise. The Model is not significant as the p-value greater than 0.05

Below figure represents the half normal plot of effects of both the polymers in drug release characteristics. 
The data interpretation shows that the model is not significant as the as the p-value is greater than " 0.05 ". Similar to other time points ANOVA interpretation and model plots reveals that the factor carbomer plays significant role in controlling the drug release characteristics at 4 Hour time point. However Povidone has got very minimal role and the factor interactions are also not significant.

\subsubsection{Significant Factors for Dissolution at 8 Hour}

Impact of polymers carbomer and povidone on drug release properties at 8 Hours were evaluated. The following ANOVA shown in Table 15 is for a model that does not adjust for curvature. This is the default model used for prediction and model plots.

The Model F-value of 6.38 implies there is a $8.11 \%$ chance that a "Model F-Value" this large could occur due to noise. Values of "Prob > F" less than 0.0500 indicate model terms are significant. In this case A are significant model

Table 14. ANOVA results of the model unadjusted for curvature.

\begin{tabular}{|c|c|c|c|c|c|c|}
\hline \multirow{2}{*}{ Source } & \multirow{2}{*}{$\begin{array}{l}\text { Sum of } \\
\text { Squares }\end{array}$} & \multirow{2}{*}{ df } & \multirow{2}{*}{$\begin{array}{l}\text { Mean } \\
\text { Square }\end{array}$} & \multirow{2}{*}{ F Value } & p-value & \multirow{2}{*}{ Remarks } \\
\hline & & & & & Prob $>$ F & \\
\hline Model & 492.92 & 3 & 164.31 & 9.04 & 0.0517 & not significant \\
\hline A-carbomer & 484.00 & 1 & 484.00 & 26.64 & 0.0141 & - \\
\hline B-Povidone & 8.92 & 1 & 8.92 & 0.49 & 0.5339 & - \\
\hline $\mathrm{AB}$ & 0.00 & 1 & 0.00 & 0.00 & 1.0000 & - \\
\hline Residual & 54.50 & 3 & 18.17 & - & - & - \\
\hline Lack of Fit & 50.00 & 2 & 25.00 & 5.56 & 0.2873 & not significant \\
\hline Pure Error & 4.50 & 1 & 4.50 & - & - & - \\
\hline Cor Total & 547.43 & 6 & - & - & - & - \\
\hline
\end{tabular}

Table 15. ANOVA results of the model unadjusted for curvature.

\begin{tabular}{|c|c|c|c|c|c|c|}
\hline Source & $\begin{array}{l}\text { Sum of } \\
\text { Squares }\end{array}$ & $\mathrm{df}$ & $\begin{array}{l}\text { Mean } \\
\text { Square }\end{array}$ & F Value & $\begin{array}{l}\text { p-value } \\
\text { Prob > F }\end{array}$ & Remarks \\
\hline Model & 932.73 & 3 & 310.91 & 6.38 & 0.0811 & not significant \\
\hline A-carbomer & 930.25 & 1 & 930.25 & 19.10 & 0.0222 & \\
\hline B-Povidone & 0.23 & 1 & 0.23 & 0.00 & 0.9492 & not significant \\
\hline $\mathrm{AB}$ & 2.25 & 1 & 2.25 & 0.05 & 0.8436 & not significant \\
\hline Residual & 146.12 & 3 & 48.71 & - & - & - \\
\hline Lack of Fit & 144.12 & 2 & 72.06 & 36.03 & 0.1170 & not significant \\
\hline Pure Error & 2.00 & 1 & 2.00 & - & - & - \\
\hline Cor Total & 1078.86 & 6 & - & - & - & - \\
\hline
\end{tabular}


terms. The "Lack of Fit F-value" of 36.03 implies the Lack of Fit is not significant relative to the pure error. There is a $11.70 \%$ chance that a "Lack of Fit F-value" this large could occur due to noise. Non-significant lack of fit is good; we want the model to fit.

Similar to the data at 4 Hour time point, data interpretation shows that the model is not significant as the as the p-value is greater than " 0.05 ".

ANOVA interpretation and model plots reveal that the factor carbomer plays significant role in controlling the drug release characteristics at 8 Hour time point. The second polymer Povidone does not carry significant impact on drug release and the factor interactions are also minimal. Below Figure 6 represents the Half normal plot on the impact of studied variables carbomer and povidone on Drug release at 1, 2, 4 \& 8 Hours. Additionally 3D graph on the impact of carbomer and povidone on Drug release at time intervals 1, 2, 4 \& 8 Hours is plotted as Figure 7.
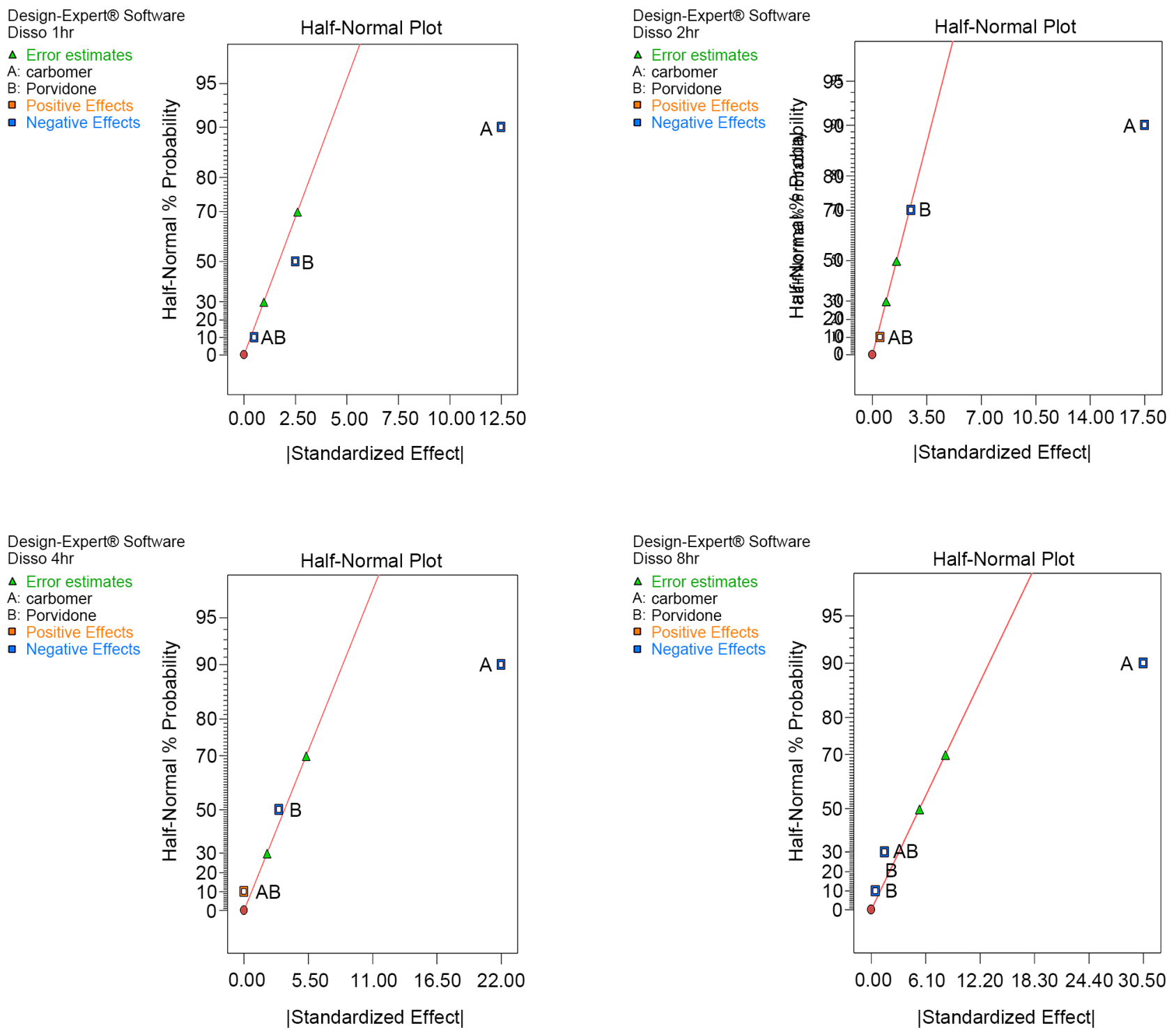

Figure 6. Half normal plot on the impact of carbomer \& povidone on drug release at 1, 2, $4 \& 8$ hours. 

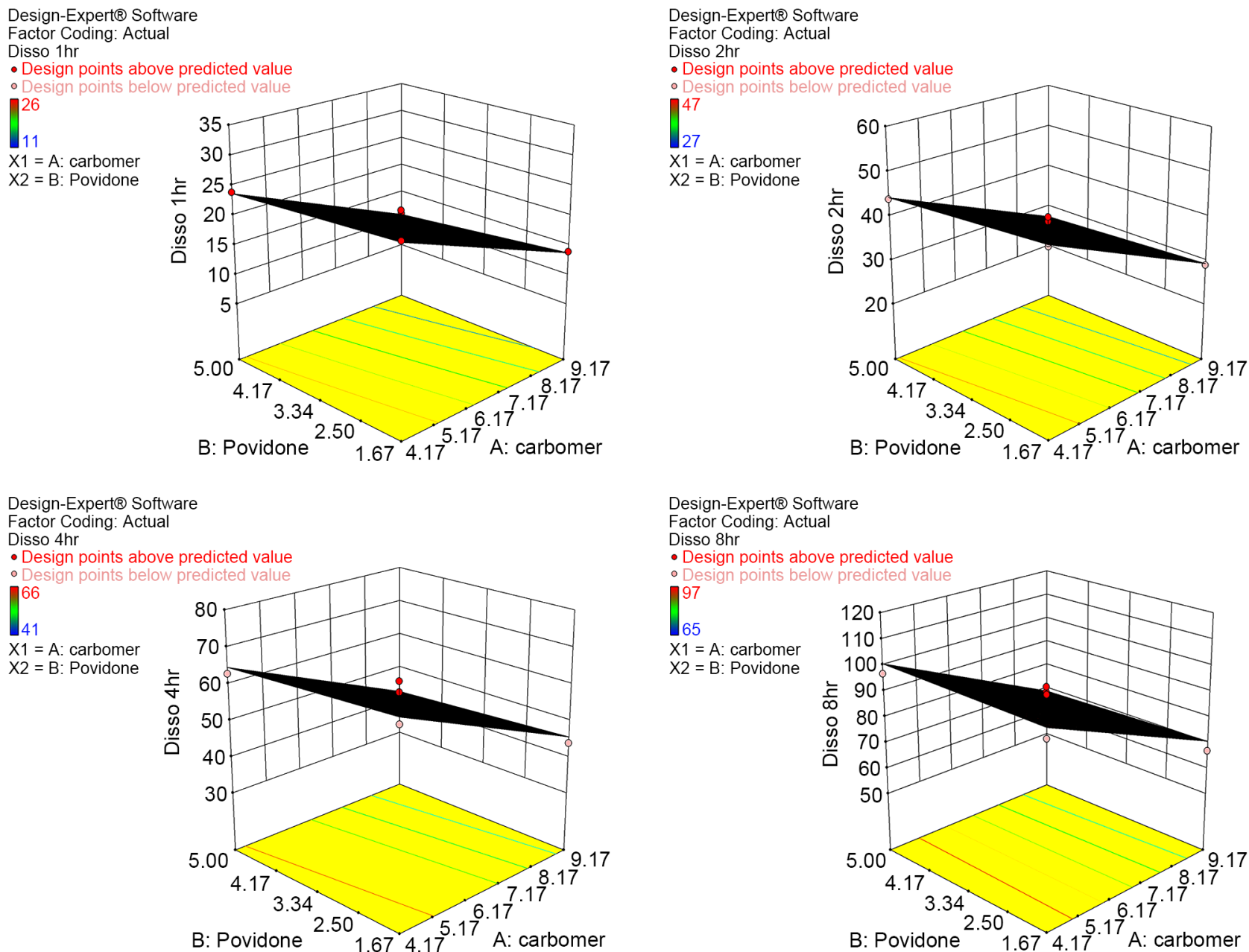

Figure 7. 3D graph on the impact of carbomer \& povidone on drug release at 1, 2, $4 \& 8$ hours.

\subsubsection{Summary of the Polymer Concentration Range Study \& Design Space}

The control release polymer carbomer had significant role in the dissolution rate at all time points studied. Increase in the concentration of carbomer had shown a reduction in drug release.

Based on analysis, the main effects and interaction effects were identified using a full factorial DoE, following design space was obtained to establish acceptable range for release controlling polymer variables. Figure 8 shows the overlay plot of all the responses. The green zone indicated that the desired responses were achieved simultaneously.

The range studied for carbomer concentration was $4.17 \%$ to $9.17 \% \mathrm{w} / \mathrm{w}$ against the second polymer Povidone at a range of $1.67 \%$ to $5.0 \% \mathrm{w} / \mathrm{w}$. The initial center points targeted for Carbomer and Povidone were 6.67\% and 3.34\% respectively, after the study it was evident that the more appropriate range would be $6.23 \%-8.2 \% \mathrm{w} / \mathrm{w}$ for carbomer and $2.88 \%-4.98 \%$ for Povidone.

\subsection{Scanning Electron Microscopy}

The Surface morphology of the carbomer and povidone based controlled release 
formulations were evaluated by scanning electron microscope (SEM) photomicrographs. The Centre point batch sample was mounted on to aluminum stub using double-sided adhesive tape and then coated with gold palladium alloy. The samples were then examined with $200 \times$ and 500 $\times$ magnification using scanning electron microscope Mini-SEM SNE-3000MB [28] [29]. Figure 9 and Figure 10 represents the SEM Photomicrograph results.

The morphology of the hydrated formulation shows that the integrity of the matrix does not remain intact once the controlled release formulation undergoes hydrodynamics for about $8-12$ Hours. Though carbomer is not a water soluble polymer, at lower concentrations the integrity of tablet matrix could not be retained in the in vitro conditions.

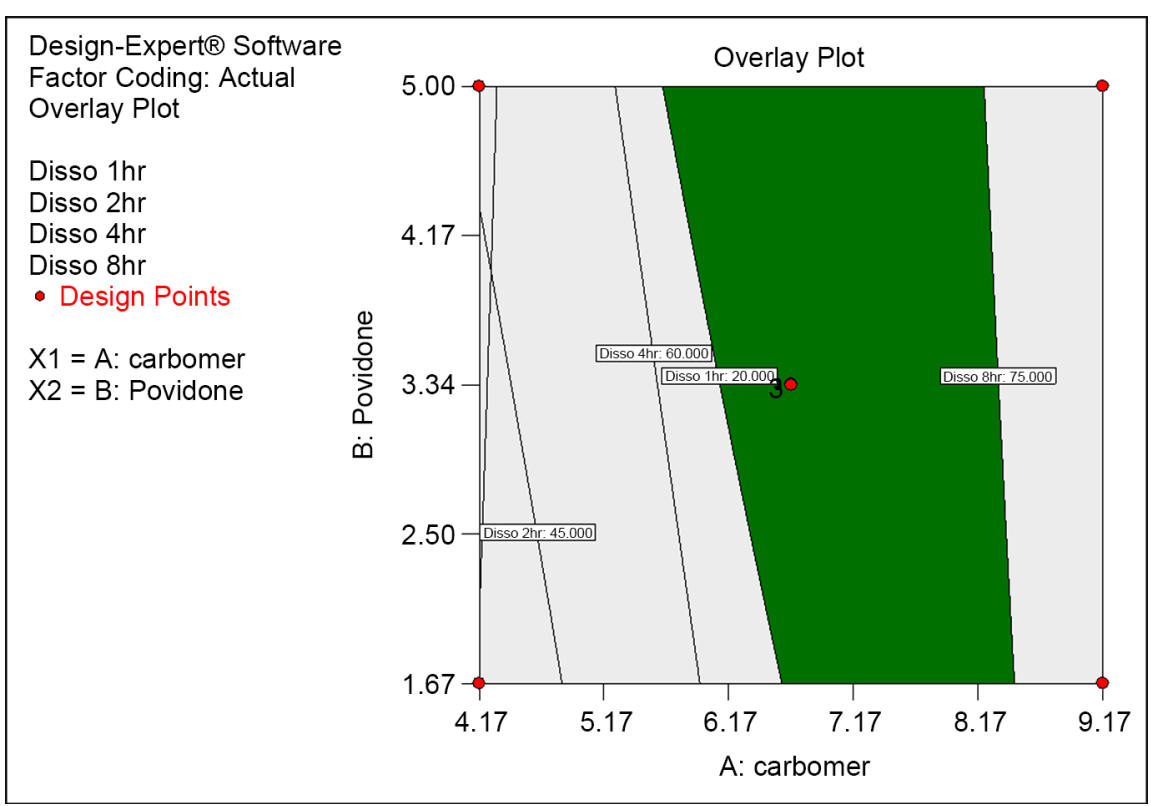

Figure 8. Overlay plot—effect of polymers on drug release properties.

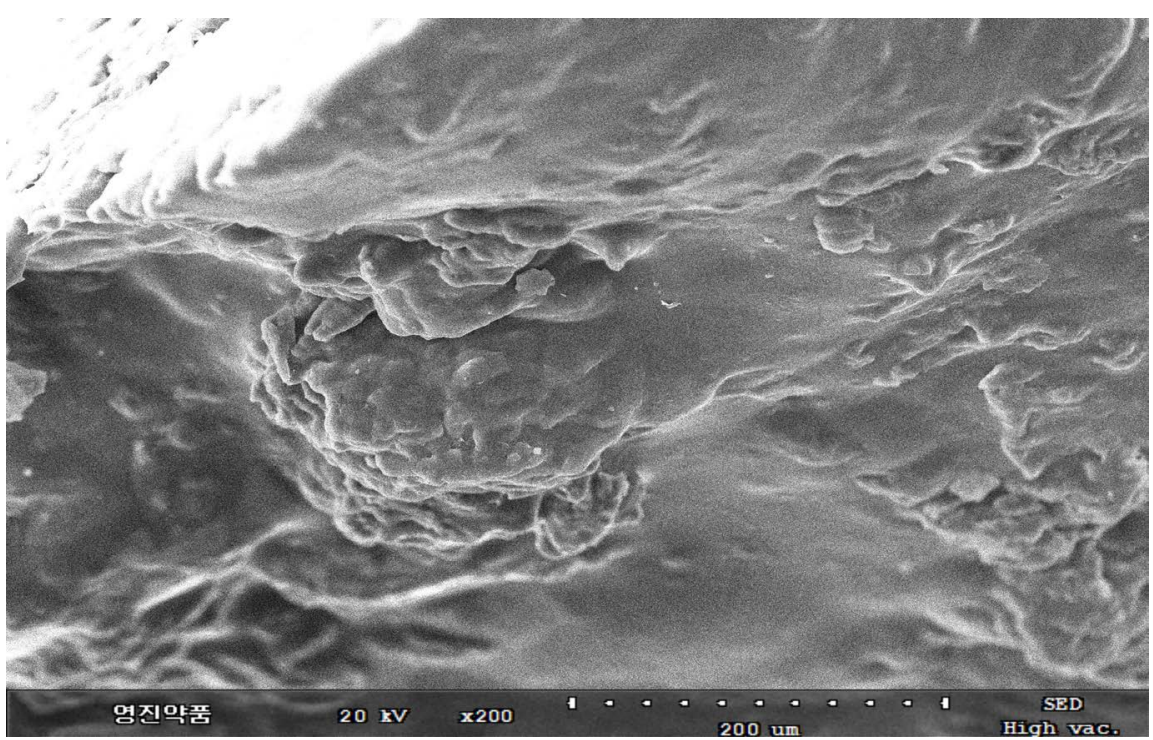

Figure 9. SEM Photomicrographs of batch number F005 at 200×. 


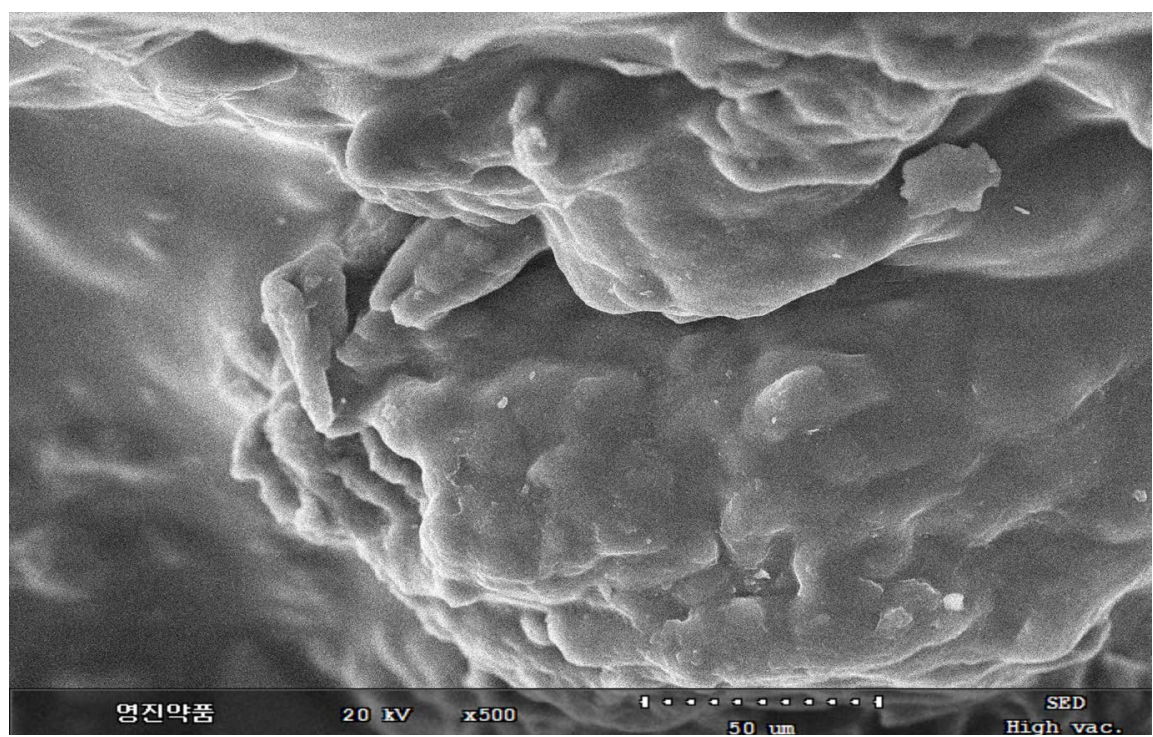

Figure 10. SEM Photomicrographs of batch number F005 at 500×.

\subsection{Ray Diffraction Spectra}

The X-ray diffraction characteristics of the controlled release monolithic tablets were evaluated and ensured that the polymorphic form remains unchanged during the manufacturing processing and on storage also.

The crystalline Atorvastatin calcium (form I) did not show any change in polymorphic character on storage irrespective of the formulation designs according to the X-ray Powder diffractograms (XRPD).The presence of Carbomer and hydrophilic Povidone did not significantly impact the solid state characteristics of the formulation on storage as well. All XRD results are represented in below Figure 11 and Figure 12.

\section{Conclusion}

The conventional monolithic controlled release matrix tablet with carbomer as release controlling polymer had shown desired drug release profile and product stability. Addition of Povidone as a gelling agent further ensures that the Carbomer-Povidone matrix maintains the integrity and prevents burst release at acidic $\mathrm{pH}$ conditions. This system ensures the maximum drug release at the alkaline $\mathrm{pH}$ region where the drug has got maximum solubility. Due to the anionic nature of the polymer, drug release from $\mathrm{Carbopol}^{\circ}$ polymer matrices is $\mathrm{pH}$ depended. By switching to the present controlled release system the extensive degradation of Atorvastatin to lactone in the acidic conditions after oral administration can be avoided. Thus we expected to have improved bioavailability similar to the studies and data presented in few peer reviewed articles [30]. Further the experimental design and optimization of polymer concentrations using Design of experiments (DOE) with Design expert ${ }^{\varpi} 6.0$ ensured that the studied range of Polymer concentration can yield desired results. Additional tweaking of Carbomer and Povidone levels as represented in the DOE overlay plot could result in an improved design. It is evident from ANOVA data that only Carbomer 


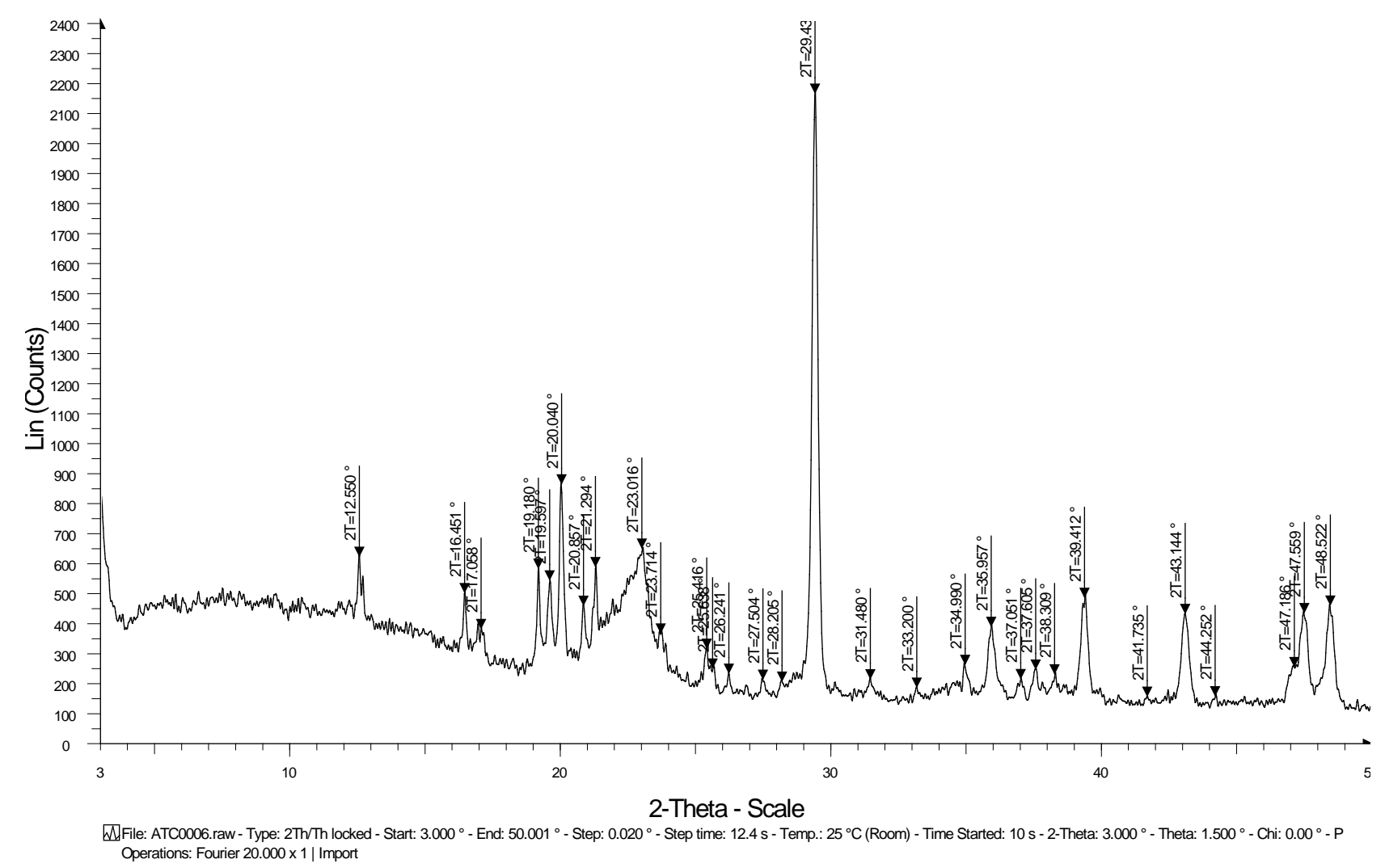

Figure 11. XRD difractogram of batch number F005-Initial.

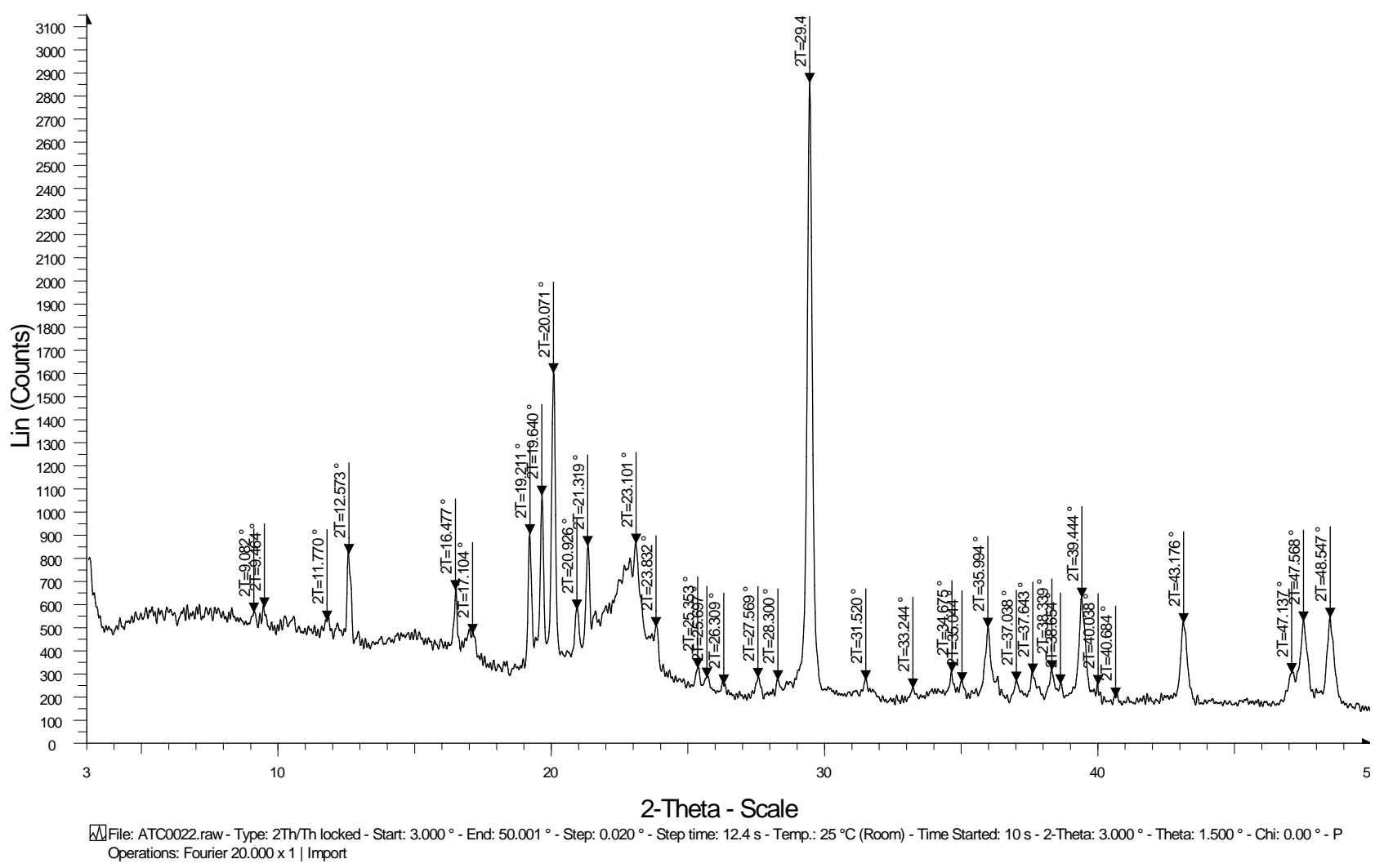

Figure 12. XRD difractogram of batch number F005-after 3 months at accelerated conditions. 
has got significant level of impact on the drug release characteristics. Hence it can be concluded that lower levels of anionic polymer Carbomer are effective in designing controlled release matrix formulations of Atorvastatin calcium tablets. However further extensive studies need to be performed to optimize the formulation and to ensure robustness during scaling up.

\section{References}

[1] Lee, V.H.L. (1987) Controlled Drug Delivery Fundamentals and Applications. In: Robinson, J.R. and Lee, V., Eds., Influence of Drug Proporties on Design, 2nd Edition, Mercel Dekker, New York, 16-25.

[2] Brahmankar, D.M. and Jaiswal, S.B. (2009) Biopharmaceutics and Pharmacokinetics. 2nd Edition, Vallabh Prakashan, Delhi, 399-401.

[3] John, C. and Mortan, C. (2002) The Science of Dosage form Design, Aulton. In: John, C. and Morten, C., Eds., Modified Release Peroral Dosage Forms, 2nd Edition, Churchil Livingston, London, 290-300.

[4] Wani, M.S., et al. (2008) Controlled Release System: A Review.

[5] Lee, M.H., et al. (2008) Preparation of Carbopol-Chitosan Interpolymer Complex as a Controlled Release Tablet Matrix. Effect of Complex Formation Medium on Drug Release Characteristics. Archives of Pharmacal Research, 31, 932-937. https://doi.org/10.1007/s12272-001-1249-7

[6] BF Goodrich Bulletin (1994) Carbopol-The Proven Polymers in Pharmaceuticals. BF Goodrich Speciality Chemicals, Cleveland.

[7] Durrani, M.J., Andrews, A., Whitaker, R. and Benner, S.C. (1994) Studies on Drug Release Kinetics from Carbomer Matrices. Drug development and Industrial Pharmacy, 20, 2439-2447. https://doi.org/10.3109/03639049409042648

[8] Khan, G.M. and Zhu, J.B. (1999) Studies on Drug Release Kinetics from Ibuprofen-Carbomer Hydrophilic Matrix Tablets: Influence of Co-Excipients on Release Rate of the Drug. Journal of Controlled Release, 57, 197-203. https://doi.org/10.1016/S0168-3659(98)00122-9

[9] Parojcic, J., Duric, Z., Jovanovic, M. and Ibric, S. (2004) An Investigation into the Factors Influencing Drug Release from Hydrophilic Matrix Tablets Based on Novel Carbomer Polymers. Drug Delivery, 11, 59-65. https://doi.org/10.1080/10717540490265379

[10] Perez-Marcos, B., Ford, J.L., Armstrong, D.J., Elliott, P.N.C., Rostron, C. and Hogan, J.E. (1996) Influence of $\mathrm{pH}$ on the Release of Propranolol Hydrochloride from Matrixes Containing Hydroxypropyl Methyl Cellulose K4M and Carbopol 974. Journal of Pharmaceutical Sciences, 85, 330-334. https://doi.org/10.1021/js950359z

[11] Khamanga, S.M. and Walker, R.B. (2005) Comparison of Method of Manufacture on the in Vitro Performance of Verapamil Matrix Tablets.

[12] Pharmaceutical Bulletin 31 Formulating Controlled Release Tablets \& Capsules with Carbopol $^{\oplus}$ Polymers.

[13] Dakkuri, A., David Butler, L. and DeLuca, P.P. (1978) Sustained Release from Inert Wax Matrixes III: Effect of Povidone on Tripelennamine Hydrochloride Release. Journal of Pharmaceutical Sciences, 67, 357-360. https://doi.org/10.1002/jps.2600670322

[14] Dave, B.S., Amin, A.F. and Patel, M.M. (2004) Gastroretentive Drug Delivery System of Ranitidine Hydrochloride: Formulation and in Vitro Evaluation. AAPSPharmSciTech, 5, 77-82. https://doi.org/10.1208/pt050234 
[15] Arza, R., Gonugunta, C. and Veerareddy, P. (2009) Formulation and Evaluation of Swellable and Floating Gastroretentive Ciprofloxacin Hydrochloride Tablets. AAPSPharmSciTech, 10, 220-226. https://doi.org/10.1208/s12249-009-9200-y

[16] Hintz, R.J. and Johnson, K.C. (1989) Modeling and Data Treatment in the Pharmaceutical Sciences. International Journal of Pharmaceutics, 51, 9. https://doi.org/10.1016/0378-5173(89)90069-0

[17] Peppas, N.A. (1985) Analysis of Fickian and Non-Fickian Drug Release from Polymers. Pharmaceutica Acta Helvetiae, 60, 110-111.

[18] Mylonaki, I., et al. (2016) Perivascular Sustained Release of Atorvastatin from a Hydrogel-Microparticle Delivery System Decreases Intimal Hyperplasia. Journal of Controlled Release, 232, 93-102. https://doi.org/10.1016/j.jconrel.2016.04.023

[19] Kumar, S., et al. (2010) Development and Validation of Reverse Phase HPLC Method for Simultaneous Estimation of Atorvastatin Calcium and Telmisartan Tablet Dosage Form. International Journal of Pharm Tech Research, 2, 463-470.

[20] Shete, G., Puri, V., Kumar, L. and Bansal, A. (2010) Solid State Characterization of Commercial Crystalline and Amorphous Atorvastatin Calcium Samples. AAPS Pharm SciTech, 11, 598-609. https://doi.org/10.1208/s12249-010-9419-7

[21] Guidance for Industry (2009) Q8(R2)Pharmaceutical Development. Center for Drug Evaluation and Research, USFDA.

[22] Balestrieri, F., et al. (1996) Application of Differential Scanning Calorimetry to the Study of Drug-Excipient Compatibility. Thermochimica Acta, 285, 337-345. https://doi.org/10.1016/0040-6031(96)02904-8

[23] Bohanec, S. et al. (2010) Using Different Experimental Designs in Drug-Excipient Compatibility Studies during the Pre-Formulation Development of a Stable Solid Dosage Formulation. Acta Chimica Slovenica, 57, 895-903.

[24] Yu, L. (2008) Pharmaceutical Quality by Design: Product and Process Development, Understanding, and Control. Pharmaceutical Research, 25, 781-791. https://doi.org/10.1007/s11095-007-9511-1

[25] Hwang, R. and Kowalski, D.L. (2005) Design of Experiments for Formulation Development Pharmaceutical Technology.

[26] Shivhare, M. and Mc Creath, G. (2010) Practical Considerations for DoE Implementation in Quality by Design.

[27] Quality by Design for ANDAs: An Example for Immediate-Release Dosage Forms. Center for Drug Evaluation and Research. USFDA.

[28] Gaura, P., Mishrab, S. and Bajpaia, M. (2014) Formulation and Evaluation of Controlled-Release of Telmisartan Microspheres: In Vitro/ in Vivo Study. Journal of Food and Drug Analysis, 22, 542-548. https://doi.org/10.1016/j.jfda.2014.05.001

[29] Rao, Y., et al. (2012) Atorvastatin Loaded Solid Lipid Nanoparticles: Formulation, Optimization, and in-Vitro Characterization. IOSR Journal of Pharmacy, 2, 23-32. https://doi.org/10.9790/3013-25102332

[30] Khan, F.N., et al. (2011) Enhanced Bioavailability of Atorvastatin Calcium from Stabilized Gastric Resident Formulation. AAPS PharmSciTech, 12, 1077-1086. https://doi.org/10.1208/s12249-011-9673-3 
Submit or recommend next manuscript to SCIRP and we will provide best service for you:

Accepting pre-submission inquiries through Email, Facebook, LinkedIn, Twitter, etc. A wide selection of journals (inclusive of 9 subjects, more than 200 journals)

Providing 24-hour high-quality service

User-friendly online submission system

Fair and swift peer-review system

Efficient typesetting and proofreading procedure

Display of the result of downloads and visits, as well as the number of cited articles Maximum dissemination of your research work

Submit your manuscript at: http://papersubmission.scirp.org/

Or contact ajac@scirp.org 